\title{
MULTIPLE CHOICE QUESTION TESTS FOR ENTRANCE EXAMINATIONS - A PROBABILISTIC APPROACH
}

Jindřich Klůfa, Nikola Kaspř́ková

\begin{abstract}
In this paper we shall analyze multiple choice question tests for entrance examinations from probability point of view. Multiple choice question tests are used for example for entrance examinations at Prague University of Economics, we shall analyze these tests at the Faculty of Business Administration. We shall report on probability methods, which can be used for modelling of these tests. In this case model of binomial distribution can be used for answering the following questions (under assumption of random choice of answers): what is the probability, that the number of correct answers exceeds given number, what is expected number of correct answers, etc. Results of this analysis can be used for consideration of the appropriateness of these tests.
\end{abstract}

\section{Key Words}

Binomial distribution, entrance examinations, examples, multiple choice question tests, probability
University of Economics, Prague jindrich.klufa@vse.cz

\section{ARTICLE INFO}

Article type

Full research paper

doi: 10.7160/eriesj.2012.050402

Article history

Received: August 17, 2012

Received in revised form: December 2, 2012

Accepted: December 9, 2012

Available on-line: December 30, 2012

Klůfa, J., Kaspř́íková, N. (2012) “Multiple Choice Question Tests for Entrance Examinations - A Probabilistic Approach", Journal on Efficiency and Responsibility in Education and Science, Vol. 5, No. 4, pp. 195-202, ISSN 1803-1617, [on-line] www.eriesjournal.com/_papers/article_189.pdf 


\section{Introduction}

Multiple choice question tests (test has $n$ questions, each question has $m$ answers) are widely used in testing knowledge of students. One of the advantages of such type of test is that the results can be evaluated quite easily even for large number of students. On the other hand, a student can obtain certain number of points in the test purely by guessing the correct answers and this fact should be considered in interpretation of test scores. This problem is addressed in education research see Zhao (2005), Premadasa (1993) and Klufa (2012).

We shall assume that the test has $n$ questions, each question has $m$ answers (one answer is correct), the wrong answer is not penalized. Such multiple choice question tests are used for example for entrance examinations at Prague University of Economics - see Klufa (2011). We shall analyze these tests at the Faculty of Business Administration (the same tests are used at the Faculty of Finance and Accounting and at the Faculty of Informatics and Statistics). Relation between results of entrance examination test and study results is not addressed in this paper, such analysis is performed e. g. in Kubanova and Linda (2012)). Note that standard (no multiple choice questions) tests, in which the student has to devise the answer by himself, are used for checking knowledge of students in mathematics courses at University of Economics - for analysis of such tests see (Kasprikova, 2011), but for entrance examinations, multiple choice questions are preferred so that the results of tests can be obtained quickly and there is clearly no impact of any subjective factor in evaluation. We provide an answer to the following questions (under assumption of random choice of answers): what is probability that number of correct answers exceeds given number and what is expected number of correct answers, etc. We shall use results of this analysis for evaluation of the appropriateness of these tests.

\section{Materials and Methods}

From probability point of view a multiple choice test means: Let us consider $n$ independent random trials (questions) having two possible outcomes, say "success" (correct answer) and "failure" (wrong answer) with probabilities $p$ and (1-p) respectively. Probability of correctly answered question $p$ (under assumption that each of $m$ answers in particular question has the same probability and just one answer is correct) is $p=1 / \mathrm{m}$.

Let us denote $X$ as number of successes that occur in $n$ independent random trials. $X$ is a discrete random variable (number of successes can be $0,1,2, \ldots, n$ ) distributed according to the binomial law with parameters $n$ and $p$. Probability that number of successes is $k$ is (see e.g. Rao, 1973)

$$
P(X=k)=\left(\begin{array}{l}
n \\
k
\end{array}\right) p^{k}(1-p)^{n-k}, k=0,1,2, \ldots, n .
$$

The expected value and the variance (dispersion) of random variable $X$ distributed according to the binomial law with parameters $n$ and $p$ is

$$
E(X)=n p, \quad D(X)=n p(1-p)
$$

The distribution function of discrete random variable $X$, i.e. probability that random variable $X$ does not exceed $x$, distributed according to the binomial law with parameters $n$ and $p$ is 


$$
F(x)=0, x<0, \quad F(x)=\sum_{k=0}^{[x]}\left(\begin{array}{l}
n \\
k
\end{array}\right) p^{k}(1-p)^{n-k}, x \geq 0
$$

where $[x]$ is integer part of $x$.

\section{Results}

Entrance examinations in mathematics

Entrance examinations in mathematics have 10 questions for 5 points and 5 questions for 10 points (100 points total). Questions are independent. Each question has 5 answers (one answer is correct), wrong answer is not penalized. Under assumption that each answer has the same probability, probability that a particular question is correctly answered is $p=1 / 5$.

Example 1. Under assumption of random choice of answers we shall find probability that number of points in the test in mathematics is 15 .

\section{Let us denote}

$\mathrm{Y}=$ number of points in the test in mathematics

$\mathrm{X}_{1}=$ number of correct answers in the first 10 issues

$\mathrm{X}_{2}=$ number of correct answers in 10-points tasks

\section{It holds}

$$
\begin{gathered}
P(Y=15)=P\left[\left(X_{1}=1 \cap X_{2}=1\right) U\left(X_{1}=3 \cap X_{2}=0\right)\right]=P\left[\left(X_{1}=1 \cap X_{2}=1\right)\right]+ \\
+P\left[\left(X_{1}=3 \cap X_{2}=0\right)\right]
\end{gathered}
$$

Random variables $X_{1}, X_{2}$ are independent, therefore we have see e.g. Rényi (1972)

$$
\mathrm{P}(\mathrm{Y}=15)=\mathrm{P}\left(\mathrm{X}_{1}=1\right) \mathrm{P}\left(\mathrm{X}_{2}=1\right)+\mathrm{P}\left(\mathrm{X}_{1}=3\right) \mathrm{P}\left(\mathrm{X}_{2}=0\right)
$$

Random variable $X_{1}$ has binomial distribution with parameters $n=10$ and $p=0,2$. Random variable $X_{2}$ has binomial distribution with parameters $n=5$ and $p=0,2$. According to (1) we obtain

$$
P(Y=15)=\left(\begin{array}{c}
10 \\
1
\end{array}\right) 0,20,8^{9}\left(\begin{array}{l}
5 \\
1
\end{array}\right) 0,20,8^{4}+\left(\begin{array}{c}
10 \\
3
\end{array}\right) 0,2^{3} 0,8^{7}\left(\begin{array}{l}
5 \\
0
\end{array}\right) 0,8^{5}=0,175922
$$

Analogously, we can calculate the probability $P(Y=k)$ for other $k=0,5,10,15, \ldots, 95,100$ (see Table 1 and Figure 1). For this calculation we have used the Mathematica software (Statistics 'DiscreteDistributions') - see Wolfram (1996)

\begin{tabular}{|c|c|c|c|}
\hline Points in the test & Probability & Points in the test & Probability \\
\hline 0 & 0,035184 & 55 & 0,002890 \\
\hline 5 & 0,087961 & 60 & 0,000957 \\
\hline 10 & 0,142937 & 65 & 0,000275 \\
\hline 15 & 0,175922 & 70 & 0,000067 \\
\hline 20 & 0,174547 & 75 & 0,000014 \\
\hline 25 & 0,146098 & 80 & 0,000002 \\
\hline 30 & 0,105227 & 85 & $3 \times 10^{-7}$ \\
\hline 35 & 0,066057 & 90 & $2 \times 10^{-8}$ \\
\hline 40 & 0,036467 & 95 & $1 \times 10^{-9}$ \\
\hline 45 & 0,017761 & 100 & $10^{-11}$ \\
\hline 50 & 0,007634 & Sum & 1,000000 \\
\hline
\end{tabular}

Table 1: Distribution of number of points in the test (mathematics) 


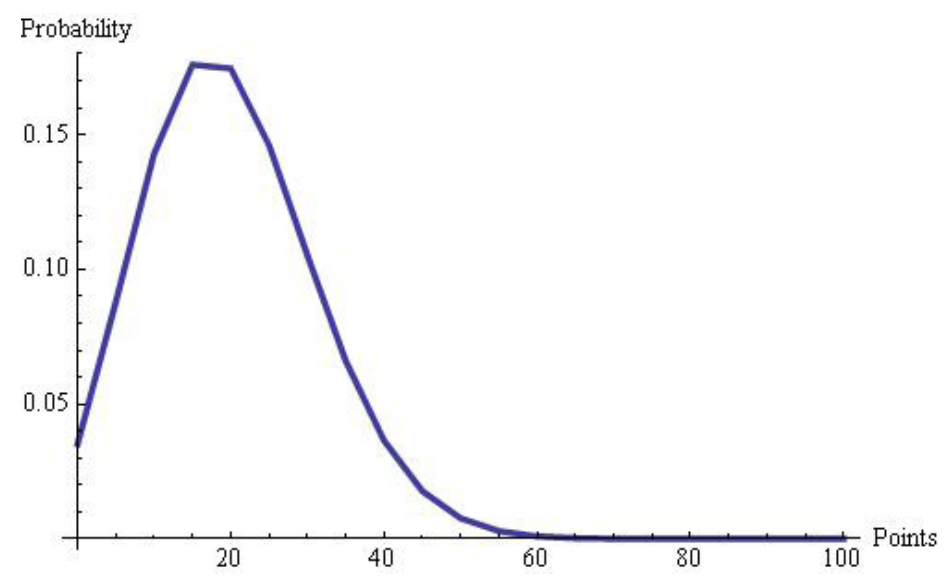

Figure 1: Distribution of number of points in the test (polygon) mathematics

Example 2. Under assumption of random choice of answers we shall find probability that number of points in the test in mathematics is
(a) 30 and more,
(b) 40 and more,
(c) 50 and more

(a) Using notation from example 1 we have - see e.g. Marek (2012)

$$
\begin{gathered}
\mathrm{P}(\mathrm{Y} \geq 30)=1-\mathrm{P}(\mathrm{Y}<30)=1-\mathrm{P}[(\mathrm{Y}=0) \mathrm{U}(\mathrm{Y}=5) \mathrm{U}(\mathrm{Y}=10) \mathrm{U}(\mathrm{Y}=15) \\
\mathrm{U}(\mathrm{Y}=20) \mathrm{U}(\mathrm{Y}=25)]=
\end{gathered}
$$

$=1-[P(Y=0)+P(Y=5)+P(Y=10)+P(Y=15)+P(Y=20)+P(Y=25)]$
Finally, from Tab.1 we obtain

$$
P(Y \geq 30)=1-0,762649=0,237351 \text {. }
$$

Under assumption of random choice of answers almost a quarter of students get the test score 30 or more points.

(b) Analogously, we obtain

$$
P(Y \geq 40)=1-P(Y<40)=
$$

$=1-[P(Y=0)+P(Y=5)+P(Y=10)+P(Y=15)+P(Y=20)+P(Y=25)+$

$$
P(Y=30)+P(Y=35)]
$$

Finally, from Tab.1

$$
P(Y \geq 40)=1-0,933933=0,066067 .
$$

Under assumption of random choice of answers approximately $6,6 \%$ of students get the test score 40 or more points.

(c) Finally

$$
P(Y \geq 50)=1-0,988161=0,011839 .
$$

Under assumption of random choice of answers approximately $1,2 \%$ of students get the test score 50 or more points.

Example 3. Under assumption of random choice of answers we shall find the expected number of points in the test in mathematics and mode.

Using notation from example 1 we have

$$
Y=5 X_{1}+10 X_{2}
$$

Therefore - see e.g. Feller (1970)

$$
E(Y)=E\left(5 X_{1}+10 X_{2}\right)=5 E\left(X_{1}\right)+10 E\left(X_{2}\right)
$$

According to (2) we obtain (e.g. $E\left(X_{1}\right)=10 \cdot 0,2=2$ )

$$
E(Y)=5.2+10.1=20
$$


Expected number of points in the test is 20. The mode is the most probable number of points. From Tab.1 is

$$
\hat{y}=15 \text {. }
$$

\section{Entrance examinations in English}

Entrance examinations in English (or other language) have 50 questions for 2 points (100 points total). Questions are independent. Each question has 4 answers (one answer is correct), the wrong answer is not penalized. Under assumption that each answer has same probability, probability that a particular question is answered correctly is $p=1 / 4$.

Example 4. Under assumption of random choice of answers we shall find probability that number of points in the test in English is 20 .

Let us denote

\section{$\mathrm{Z}=$ number of points in the test in English}

$\mathrm{X}=$ number of correct answers in the 50 issues

Random variable $X$ has binomial distribution with parameters $n=50$ and $p=0,25$. According to (1) we obtain

$$
P(Z=20)=P(X=10)=\left(\begin{array}{l}
50 \\
10
\end{array}\right) 0,25^{10} 0,75^{40}=0,098518
$$

Analogously, we can calculate the probability $P(Z=k)$ for other $k=0,2,4,6,8, \ldots, 98,100 \quad$ - see Table 2 (only for $k=0, \ldots, 66$, other probabilities are less than $10^{-9}$ ) and Figure 2. For this calculation we have used the Mathematica software (Statistics

\begin{tabular}{|c|c|c|c|}
\hline Points in the test & Probability & Points in the test & Probability \\
\hline 0 & 0,000001 & 36 & 0,026390 \\
\hline 2 & 0,000009 & 38 & 0,014816 \\
\hline 4 & 0,000077 & 40 & 0,007655 \\
\hline 6 & 0,000411 & 42 & 0,003645 \\
\hline 8 & 0,001610 & 44 & 0,001602 \\
\hline 10 & 0,004938 & 46 & 0,000650 \\
\hline 12 & 0,012345 & 48 & 0,000244 \\
\hline 14 & 0,025865 & 50 & 0,000084 \\
\hline 16 & 0,046341 & 52 & 0,000027 \\
\hline 18 & 0,072087 & 54 & 0,000008 \\
\hline 20 & 0,098518 & 56 & 0,000002 \\
\hline 22 & 0,119416 & 58 & 0,000001 \\
\hline 24 & 0,129368 & 60 & ${ }_{10-7^{1}} \mathrm{x}$ \\
\hline 26 & 0,126050 & 62 & $3 \times 10-8$ \\
\hline 28 & 0,111044 & 64 & $6 \times 10-9$ \\
\hline 30 & 0,088836 & 66 & $1 \times 10-9$ \\
\hline 32 & 0,064776 & $* * *$ & $* * *$ \\
\hline 34 & 0,043184 & Sum & 1,000000 \\
\hline
\end{tabular}
'DiscreteDistributions') - see Wolfram (1996).
Table 2: Distribution of number of points in the test (English) 


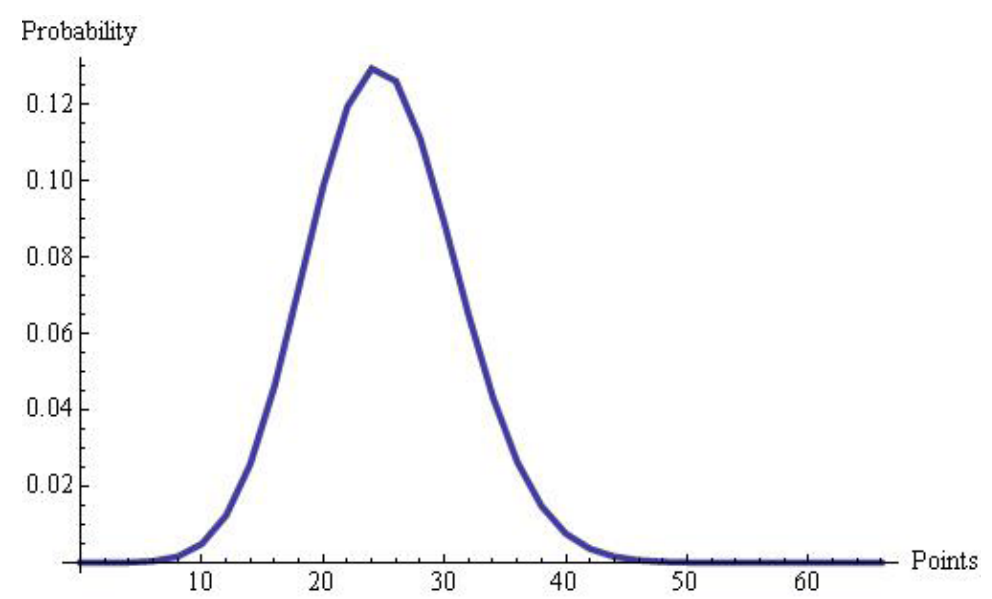

Figure 2: Distribution of number of points in the test (polygon) English

Example 5. Under assumption of random choice of answers we shall find probability that number of points in the test in English is

(a) 30 and more,

(b) 40 and more,

(c) 50 and more.

(a) Using notation from example 4 we have $P(Z \geq 30)=1-P(Z<30)==1-[P(Z=0)+P(Z=2)+P(Z=4)+\ldots+$ $P(Z=26)+P(Z=28)]$

Finally, from Tab.2 we obtain

$$
P(Z \geq 30)=1-0,748080=0,251920 .
$$

Under assumption of random choice of answers approximately quarter of students get the test score 30 or more points.

(b) Analogously, from Tab.2 we obtain

$$
P(Z \geq 40)=1-P(Z<40)=1-0,986082=0,013918 .
$$

Under assumption of random choice of answers approximately $1,4 \%$ of students get the test score 40 or more points.

(c) Finally

$$
P(Z \geq 50)=1-0,999878=0,000122 .
$$

Under assumption of random choice of answers approximately $0,01 \%$ of students get the test score 50 or more points.

Example 6. Under assumption of random choice of answers we shall find the expected number of points in the test in English and mode.

Using notation from example 4 we have $Z=2 X$. According to (2) we obtain

$$
E(Z)=E(2 X)=2 E(X)=2.12,5=25 .
$$

The expected number of points in the test in English is 25. The mode is the most probable number of points. From Tab. 2 is

$$
\hat{z}=24 \text {. }
$$

\section{Discussion}

Real results of entrance examinations in 2012 are in Figure 3 (mathematics) and Figure 4 (English or other language). For example, a mean number of points in the test in mathematics is 64,7 (expected number of points in the test, under assumption of random choice of answers, is 20 - see results of Example 3). Similarly, a mean number of points in the test in English or 
other language is 68,0 (expected number of points in the test, under assumption of random choice of answers, is 25 - see results of Example 6). The results obtained are valid under the assumption of random choice of answers (pure guessing). In such cases, each of $m$ answers has the same probability and questions are independent.

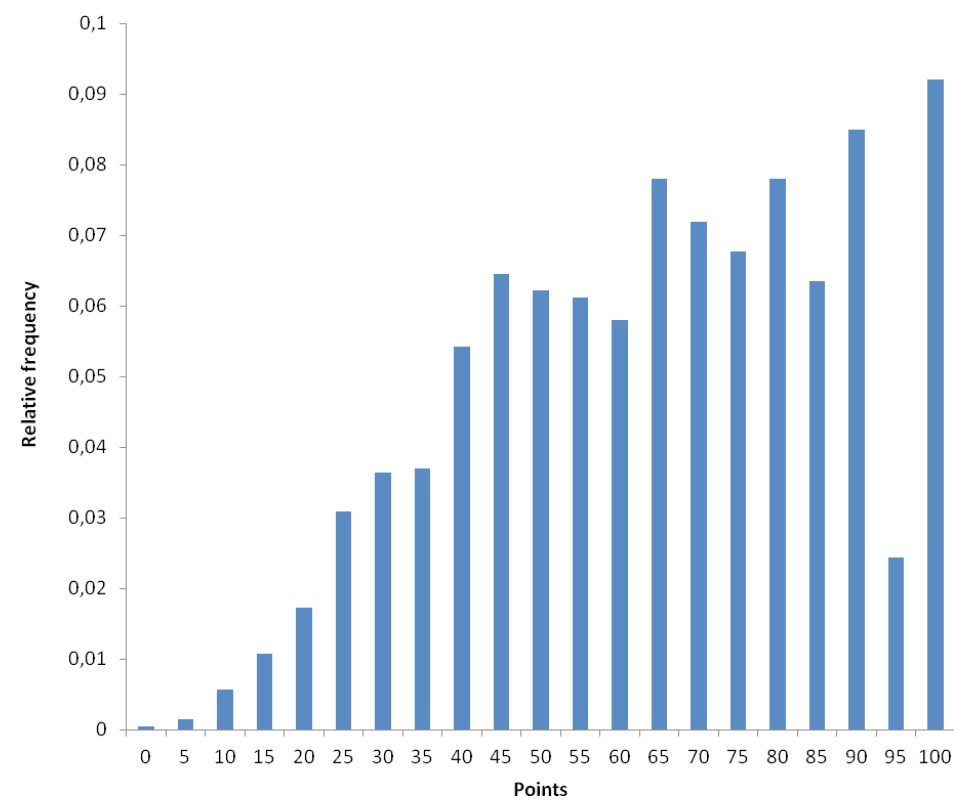

Figure 3: Real distribution of number of points in mathematics in 2012 (histogram)

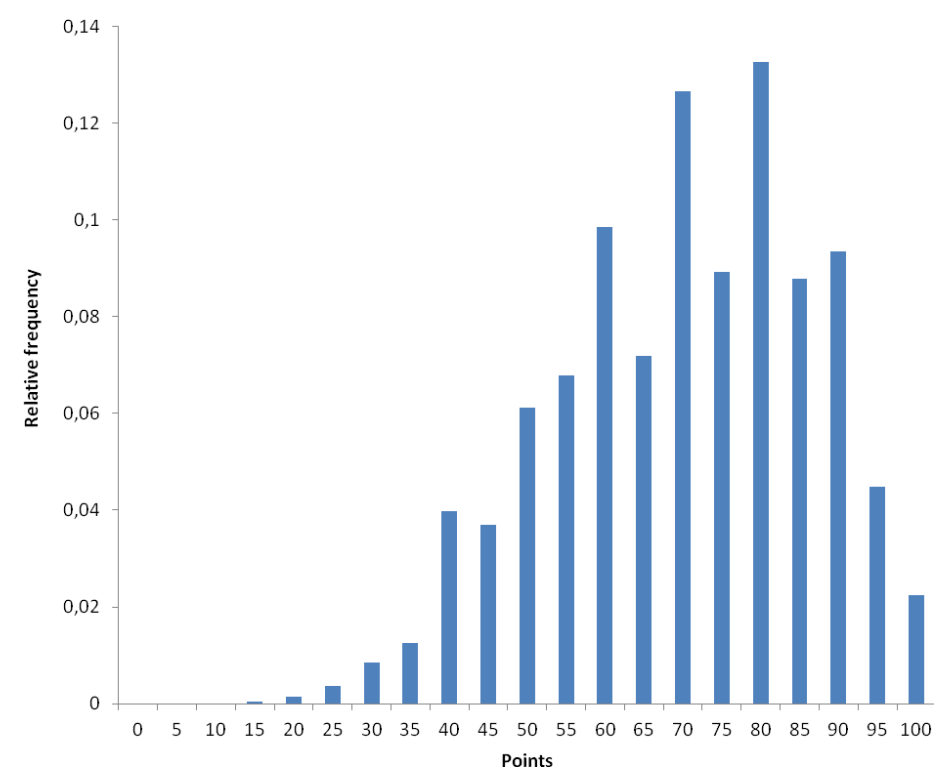

Figure 4: Real distribution of number of points in English or other language in 2012 (histogram)

\section{Conclusion}

Random variables $Y$ (number of points in the test in mathematics) and $Z$ (number of points in the test in English) are independent. Therefore, under the assumption of random choice of answers, probability that number of points in both tests (mathematics and English) is 50 and more is (see results of Example 2 and Example 5)

$\mathrm{P}(\mathrm{Y} \geq 50) \mathrm{P}(\mathrm{Z} \geq 50)=0,011839 \times 0,000122=0,000001$. 
It means that approximately one student in a million (without any knowledge) successfully passes the entrance examinations at University of Economics. Multiple choice question tests are suitable for entrance examinations at University of Economics. These tests are objective (there is clearly no impact of any subjective factor in evaluation). Moreover, results can be evaluated quite easily for large number of students. Results of this paper show that risk of success of students with lower performance levels is negligible.

\section{References}

Feller, W. (1970) An Introduction to Probability Theory and its Application. New York: John Wiley.

Kaspř́íková, N. (2011) 'Multivariate Analysis of Examination Papers', Efficiency and Responsibility in Education 2011, Proceedings of the 8th International Conference, Prague, pp. 120-127.

Klůfa, J. (2011) Mathematics for entrance examinations at University of Economics, Prague: Ekopress

Klůfa, J. (2012) 'Tests from probability point of view', Efficiency and Responsibility in Education 2012, Proceedings of the 9th International Conference, Prague, pp. 229-233.

Kubanová, J., Linda, B. (2012) 'Relation between results of the learning potential tests and study results', Journal on Efficiency and Responsibility in Education and Science, vol. 5, no 3, pp.125134.

Marek, L. (2012) Pravděpodobnost, Prague: Professional Publishing

Premadasa, I. (1993) 'A reappraisal of the use of multiple-choice questions', Medical Teacher, vol. 15, no. 2-3, pp. 237-242.
Rao, C.R. (1973) Linear Statistical Inference and Its Applications, New York: John Wiley

Rényi, A. (1972) Teorie pravděpodobnosti. Prague:Academia.

Wolfram, S. (1996) Mathematica. Addison-Wesley.

Zhao, Y. (2005) 'Algorithms for converting raw scores of multiple-choice question tests to conventional percentage marks', International Journal of Engineering Education, vol. 21, no. 6, pp. 1189-1194. 